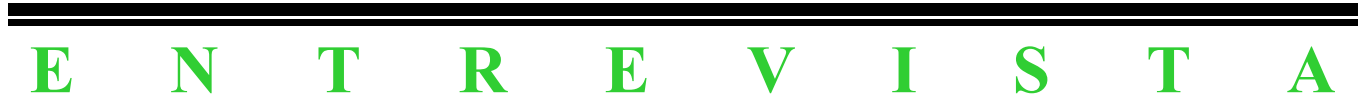




\section{ENTREVISTA A EUGENIO BULYGIN}

Hay dos circunstancias de tu historia que son especialmente destacables. Por un lado, en lo que respecta al inicio de tu formación, representas un ejemplo notable de adaptación rápida y fructifera a un medio humano e intelectual novedoso: un joven europeo que arriba a Buenos Aires, sin conocer prácticamente el castellano, y que a los pocos años se convierte en un referente obligado de la comunidad jusfilosófica argentina y, poco más tarde, de la comunidad internacional. Por el otro, tuviste que superar las condiciones adversas de dictaduras militares durante el desarrollo de tu carrera académica. Sería interesante que nos relataras aspectos de ambas experiencias.

Los primeros años de mi vida fueron un tanto azarosos, cosa que ha ocurrido a mucha gente de mi generación. He nacido en 1931 en un país hoy inexistente: la Unión Soviética. Antes de haber cumplido 10 años estalló la guerra con Alemania, que tuvo un comienzo desastroso; los alemanes ocuparon en pocos meses buena parte de la URSS, inclusive la ciudad donde vivíamos nosotros. En 1943 fuimos deportados a Alemania; al finalizar la guerra en 1945 mis padres resolvieron no regresar a Rusia. Durante algunos años vivimos en Austria, donde reinicié mis estudios, interrumpidos por los sucesos bélicos. En 1949 llegamos a Buenos Aires; tenía 17 años. Los comienzos no fueron fáciles, pues ni siquiera conocía el idioma del país en que me tocaba vivir. Pero la falta de conocimiento del castellano fue compensada en cierto modo por mis conocimientos de ajedrez, que había empezado a practicar asiduamente en Austria. Gracias al ajedrez establecí mis primeros contactos con el nuevo entorno. Durante algunos años he sido un frecuente visitante del Club Argentino de Ajedrez en la época en que Najdorf era el indiscutible campeón y Panno hacía sus primeras armas. Hasta que, ya 
familiarizado con el idioma, resolví recomenzar mis estudios, suspendidos al irnos de Austria, sin que hubiera alcanzado a terminar la escuela secundaria. Tuve que rendir de nuevo todas las materias, puesto que en aquella época no existían relaciones diplomáticas con Austria y, en consecuencia, mis estudios no fueron reconocidos. Por fin, en 1953 terminé el bachillerato y ese día resolví abandonar el ajedrez, que me insumía demasiado tiempo. No he jugado nunca más «en serio», pero no he perdido la afición: aún hoy el ajedrez me apasiona.

Después de muchas dudas, resolví estudiar derecho, una solución un tanto ecléctica (me interesaban filosofía y matemáticas, consideradas carreras poco prácticas), de la que, sin embargo, nunca me he arrepentido. Ya como estudiante tomé contacto con la Filosofía del Derecho y conocí a Cossio, a la sazón catedrático de Filosofía jurídica y director del Instituto de Filosofía del Derecho. En 1956, Ambrosio Gioja sucedió a Cossio y el encuentro con Gioja marcó toda mi vida. Gioja era un maestro excepcional, una personalidad muy brillante, quien en poco tiempo logró reunir un gran número de discípulos alrededor de su cátedra. Yo he colaborado con él desde el comienzo: primero oficiosamente como ayudante alumno y, luego de recibirme de abogado en 1958, como docente. En 1960 fui nombrado profesor adjunto (lo que equivale a titular en España) de Filosofía del Derecho en la cátedra de Gioja. Nunca más me alejé de la Filosofía del Derecho. Gracias a las becas de la Fundación Alexander von Humboldt y del British Council pude pasar un año (1963-64) en Alemania (en Colonia y Bonn), donde trabajé con Ulrich Klug y Hans Welzel, y otro en Oxford (1968-69), donde mi supervisor fue H. L. A. Hart.

El cambio de país es una operación dolorosa y complicada, como pueden atestiguar no pocos españoles en la época de la guerra civil y latinoamericanos en tiempos más recientes. Tuve que pasar dos veces por esta experiencia y tal vez sea ésta la explicación del porqué de mi adaptación rápida y firme en la Argentina. Parte del mérito corresponde al país (abierto y hospitalario), pero básicamente se debe al saludable horror que me ha quedado de mis experiencias anteriores.

Esto explica también por qué durante las diversas dictaduras que me tocó vivir en la Argentina nunca me sentí tentado a emigrar (cuando muchos de mis amigos lo hacían). Debo agregar, sin embargo, que, contrariamente a lo que sucedió a muchos de mis colegas, no fui molestado en el ejercicio de mi cátedra por las numerosas intervenciones que sufrió la universidad bajo los gobiernos militares y peronistas, cosa que sin duda facilitó mi decisión de no abandonar el país. 
En varias oportunidades vivimos situaciones muy dramáticas, especialmente en 1966, cuando se produjo la famosa «noche de los bastones largos» (en la cual la dictadura de Onganía intervino la Universidad y la policía apaleó a profesores y alumnos de la Facultad de Ciencias Exactas). Numerosos profesores renunciaron en señal de protesta. El llamado «grupo Gioja» adoptó una decisión colectiva y resolvió permanecer en la universidad. Yo voté por la renuncia, pero acaté la decisión de la mayoría. Fue una decisión difícil, sobre todo porque muchos amigos que pensaban igual que nosotros renunciaron (entre ellos Genaro Carrió, Gregorio Klimovsky, Eduardo Rabossi y Enrique Bacigalupo) у уо temía que esta discrepancia política iba a repercutir en las relaciones personales, pero felizmente esto no ocurrió.

2. Muchas personas estarían dispuestas a concebir la labor intelectual de un filósofo como una empresa estrictamente individualista. Tu trabajo con Carlos Alchourrón es uno de los casos que demuestra lo errado de esa concepción. Sin duda, trabajar de esta manera requiere resolver algunos problemas de coordinación y hasta de tipo personal. ¿Nos podrías contar la manera en que abordaron esa tarea conjunta, evidentemente enriquecedora?

Es cierto que los filósofos en general y los del derecho en particular suelen trabajar en forma individual; sin embargo, esta regla admite numerosas excepciones. Entre los lógicos las colaboraciones son bastante frecuentes (basta recordar el caso de Russell y Whitehead) y en algunas ciencias nuevas, como la inteligencia artificial, diría que es la regla. También en Filosofía del Derecho cabe observar el mismo fenómeno: Roberto Vernengo ha publicado varios trabajos colectivos, Ricardo Guibourg es coautor de varios libros escritos en colaboración; últimamente Cristina Redondo, José Juan Moreso y Pablo Navarro han publicado numerosos trabajos realizados en equipos de dos o tres coautores.

Es indudable que el trabajo conjunto de varias personas requiere ciertas condiciones especiales (por ejemplo, amistad personal, coincidencias básicas en los enfoques, etc.), pero ofrece también importantes ventajas, como la posibilidad de discutir los problemas durante su elaboración. Personalmente me gusta mucho esta modalidad de trabajo y con Carlos Alchourrón resultó especialmente fructífera.

Acerca de la forma de trabajo en equipo difícilmente se podrá dar reglas generales. Seguramente cada equipo elige el procedimiento que más le conviene. Nosotros con Alchourrón hemos seguido el siguiente método: primero discutimos un tema, luego se redacta una versión preliminar que se discute nuevamente. Se introducen las 
correcciones o se redacta una nueva versión y seguimos discutiendo hasta quedar satisfechos los dos con el trabajo. Este método tiene la desventaja de ser un tanto lento, pero tiene dos enormes virtudes: es divertido y los resultados suelen ser bastante mejores de los que se hubieran alcanzado con un trabajo estrictamente individual.

3. En relación con la noción «validez», entendida como pertenencia a un sistema jurídico, subsiste la cuestión de saber cuál es el status sistemático de las soluciones individuales, $i$. e. las que se siguen del sistema más los enunciados que describen casos particulares. Recientemente, en tu ponencia en el III Kelsen Symposium, Siena, 1991, denominada «Cognition and Interpretation of Law», sostienes explícitamente que «... Así, Kelsen tiene razón cuando dice que la validez de una norma individual no puede ser lógicamente inferida de la validez de una norma general; la norma individual, para ser válida, i. e. para pertenecer al sistema jurídico, debe ser promulgada por una autoridad competente, en nuestro caso por un juez...» (págs. 11-12). Si te he entendido bien, esta afirmación equivale a decir que un jurista no podría afirmar que una solución definida para un caso particular constituye una «norma válida» en relación a un definido sistema, hasta que un juez no la adopte como el contenido de su decisión. Ello es congruente con el escepticismo kelseniano acerca de una lógica de normas, pero sinceramente no veo claro cómo esa idea puede ser compatible con el teorema de deducción que forma parte de la noción de "consecuencia lógica» propuesta en "Normative Systems»y, en consecuencia, con la caracterización de los sistemas normativos como sistemas deductivos. Porque negar la validez de una solución (norma individual) $R$ para un caso $C$ individual, cuando $R$ se sigue lógicamente del sistema $S$ más la descripción de $C$, ¿no es lo mismo que negar la «validez» (esto es, la pertenencia a $S$ ) del condicional «Si C entonces R», a pesar de que se infiera efectivamente de S? Esto es, ¿no equivale a abandonar la relación de implicación (o de consecuencia lógica) como criterio de pertenencia?

Lo que yo dije en la frase que citas no es incompatible con el teorema de deducción, ni con la caracterización de los sistemas normativos como sistemas deductivos. Lo que sucede es que con la expresión «norma individual» nos referimos a veces a normas distintas. Para aclarar lo que quiero decir recurriré a un ejemplo: Supongamos que el Código Penal contiene una norma general conforme a la cual el que matare a otro debe ser sancionado con prisión de 8 a 25 años. Esta norma individual es una consecuencia lógica de la norma general aludida y de la proposición fáctica referida a Juan (se trata de una norma individual derivada). Cabe preguntarse: ¿qué es exactamente 
lo que dispone esa norma y quién es su destinatario? En una interpretación razonable se diría que esa norma se dirige a los órganos encargados de la administración de justicia, es decir, a los tribunales, y establece que el juez competente debe sancionar a Juan. ¿Cómo cumple el juez esta obligación? Pues dictando la sentencia (previo cumplimiento de todas las etapas procesales) respecto de Juan y, si encuentra que hay pruebas suficientes, condenándolo a una determinada pena de prisión (no ya de 8 a 25 años). Además, el juez debe fundar su decisión en la norma general del Código Penal. En otras palabras, el juez debe emitir una nueva norma individual, basada en la norma general correspondiente, condenando a Juan. Esta nueva norma individual, que constituye la parte dispositiva de la sentencia, es válida si se cumplen al menos dos condiciones: 1) que haya sido dictada por el juez competente y 2) que sea consecuencia lógica de la norma general aplicada y de las proposiciones descriptivas de los hechos del caso. Una vez dictada esa sentencia, surge el deber (establecido en otras normas generales) de los órganos administrativos pertinentes de encerrar a Juan y mantenerlo en prisión durante el tiempo fijado en la sentencia. Lo cual quiere decir que la norma individual dictada por el juez está dirigida a los órganos administrativos encargados de cumplir las decisiones judiciales.

Antes de la sentencia judicial tenemos, pues, una situación con un cierto aire de paradoja: Juan debe ser castigado y Juan no debe ser castigado. Pero el aire de paradoja se desvanece tan pronto explicitamos el contenido de esas normas. Juan debe ser castigado en el sentido de que el juez competente debe condenarlo a una pena de prisión, pero Juan no debe ser castigado en el sentido de que no debe ir a la cárcel, hasta tanto un juez competente lo haya condenado. El sujeto del deber de la primera norma es el juez: él debe sancionar a Juan. Los destinatarios de la segunda norma son, en cambio, los órganos administrativos encargados de cumplir las decisiones judiciales. Estos órganos no deben (= les está prohibido) sancionar a Juan mientras éste último no haya sido condenado por el juez. La norma general dirigida a los órganos administrativos dice que si y sólo si una persona ha sido condenada por un juez competente, ellos deben mantenerla en prisión durante el tiempo de la condena. De esta norma y del hecho que Juan haya sido condenado, por ejemplo, a 12 años de prisión se infiere una norma individual que obliga a los órganos administrativos a mantener a Juan en prisión durante 12 años. Pero mientras Juan no haya sido condenado, no sólo no deben encerrarlo en la prisión, sino que les está prohibido hacerlo.

Esto muestra que las dos normas individuales («Juan debe ser sancionado» y «Juan no debe ser sancionado») no son contradictorias, pues su contenido y sus destinatarios son distintos. 
En la frase que citas, al hablar de Kelsen me refiero a la sentencia judicial: obviamente su validez requiere que haya sido dictada por el juez competente. En cambio, no se exige este requisito para la validez de la norma individual que obliga al juez a condenar a Juan.

4. En «Normative Systems» (1971) tú y Carlos Alchourrón han propuesto distinguir a la ciencia jurídica de las otras ciencias, por el tipo de explicación racional que la caracteriza, esto es, por la naturaleza de las respuestas a sus problemas teóricos. Estos son presentados como interrogantes acerca de los calificativos deónticos que les corresponden a ciertas acciones de acuerdo a un definido sistema normativo. Consecuentemente, proponen denominar genéricamente «justificación normativa» a los resultados (o al menos, a parte de los resultados) de la actividad de los juristas, en forma análoga a la "explicación causal» propia de las ciencias empíricas o la «prueba» en las ciencias formales. Una justificación normativa consiste en mostrar que un calificativo deóntico para una conducta se infiere del sistema en cuestión. Sin embargo, por un lado, el término «justificación» no parece apropiado para dar cuenta de una actividad presuntamente cognoscitiva. Y por el otro, en la medida en que el mismo modelo parece servir también para reconstruir la forma de justificación de las decisiones judiciales, no habría distinción que hacer entre la dogmática y la actividad de los jueces. En ambos casos se usa un sistema de normas para inferir soluciones, $i$. e. normas generales o individuales. Lo que sugiere que tratan con problemas de idéntica clase. Por ello, ambas respuestas tendrían también carácter normativo por cuanto constituyen resultados de inferencias lógicas efectuadas a partir de sistemas normativos. ¿Cuál sería, entonces, el criterio -si es que lo hay-para distinguir la actividad de los juristas de la de los jueces? ¿En qué sentido puede decirse que los juristas describen normas, si es que sus respuestas tienen carácter normativo?

La principal diferencia entre los juristas o científicos del derecho y los jueces consiste en que estos últimos dictan normas, mientras que los primeros se limitan a mostrar qué consecuencias se infieren de las normas generales existentes. La ciencia del derecho no se ocupa de casos concretos, sino de lo que en Normative Systems fue denominado casos genéricos y procura mostrar qué consecuencias normativas se derivan de las normas generales para esos casos. En cambio, los jueces deben resolver casos individuales; como ya indiqué en mi respuesta a la pregunta anterior, para hacerlo no basta derivar una solución para ese caso individual, sino que es necesario dictar una norma individual, condenando o absolviendo al acusado o al demandado. 
En este sentido hay una cierta analogía entre la actividad del jurista y la del juez: ambos infieren consecuencias normativas. Es esto lo que justifica utilizar la expresión «justificación normativa» al referirse a la ciencia del derecho. Pero el juez no se limita a inferir consecuencias de las normas generales del sistema: dicta, además, normas individuales, que -como he mostrado en mi respuesta anterior- son distintas de las normas individuales que infiere la ciencia jurídica. Y es aquí donde hay una diferencia esencial entre las dos actividades; ambas son normativas, en el sentido de que tienen que ver con normas, pero la actividad del juez es, además, normativa en un sentido mucho más fuerte: el juez dicta normas, cosa que el jurista no hace.

Por otra parte, cabe calificar la actividad del jurista como descriptiva o cognoscitiva: ¿en qué otra cosa puede consistir la descripción (el conocimiento) de un sistema normativo, sino en desplegar sus consecuencias normativas para los diversos casos genéricos? (Este proceso fue descrito con algún detalle en Normative Systems).

5. En un artículo ya clásico, tú y Carlos Alchourrón, en relación a la discusión acerca de la naturaleza ontológica de las normas, propusieron lo que denominaron "concepción expresiva», como alternativa a una concepción hilética. Alli se muestra de qué manera es posible dar cuenta, con ese punto de vista, de importantes problemas, en especial, el que se refiere a la aplicación de la lógica a los lenguajes normativos. Esta propuesta constituyó un cambio con respecto a trabajos anteriores. Sin embargo, últimamente has puesto en duda la fertilidad de esa concepción a la hora de dar respuesta a ciertos problemas. ¿Nos podrías especificar cuáles son esas cuestiones en las que se manifiesta esa insuficiencia? Tus dudas actuales ¿te conducen, entonces, a optar nuevamente por una concepción hilética acerca de las normas?

El artículo que mencionas surgió de la observación de que entre los autores que se ocupan de las normas (lógicos deónticos, filósofos jurídicos o morales) cabe distinguir dos concepciones básicas que hemos denominado concepción hilética y concepción expresiva. Todos están de acuerdo en que hay dos componentes en las normas: un componente descriptivo (una proposición prescriptivo de una acción o de un estado de cosas) y un componente descriptivo. El desacuerdo versa sobre la naturaleza de este último. Los partidarios de la concepción hilética consideran que el componente prescriptivo forma parte del contenido conceptual de la norma: la norma sería algo así como el significado de un enunciado descriptivo. Simbolizamos las normas en esta concepción con «O»: «Op» es un enunciado que significa que p debe ser. 
En cambio, en la concepción expresiva, para la que usamos el símbolo «!» no hay significados prescriptivos: «!p» indica (pero no dice) que el enunciado descriptivo p fue usado para prescribir. El componente prescriptivo «!» no forma parte del contenido conceptual de la expresión «!p»; es un mero indicador pragmático de que el que emitió p realizó el acto de prescribir. En esta concepción las normas no son un tipo de enunciados, sino actos. En consecuencia, «!p» no expresa una proposición; no puede ser negada, ni unirse a otras expresiones mediante conectivas proposiciones. «-!p» $\mathrm{o}$ «!p.!q» son expresiones mal formadas, carentes de sentido. Un sistema normativo es caracterizado no como un conjunto de normas, sino como un conjunto de proposiciones que fueron ordenadas o prescriptas por la autoridad normativa.

Comprobamos además (no sin asombro) que a diferencia de los lógicos, los filósofos del derecho en su inmensa mayoría parecen compartir la concepción expresiva. Nos propusimos entonces explorar los alcances conceptuales y las limitaciones de esa concepción. De modo que no es del todo exacto decir que hemos propuesto una concepción expresiva como alternativa a la concepción hilética.

Esta exploración condujo a algunos descubrimientos interesantes. La forma más primitiva de la concepción expresiva es la teoría que concibe las normas como imperativos expresiva es la teoría que concibe las normas como imperativos u órdenes. Tal teoría, que cuenta con una tradición venerable en la Filosofía del Derecho por lo menos desde Austin, no puede dar cuenta del fenómeno de la derogación y de las normas permisivas. Esto nos llevó a la idea de postular el acto de rechazo, análogo al acto de prescribir o imperar. Enriquecida de esta manera (perfectamente compatible con el espíritu de la concepción expresiva) la teoría puede dar cuenta de ambos fenómenos. Mediante el acto de prescribir la autoridad manifiesta su voluntad de que nuevas proposiciones ingresen en el sistema; mediante el acto de rechazo la autoridad manifiesta su voluntad de que determinadas proposiciones no formen parte del sistema. Si tal proposición pertenece al sistema, debe ser eliminada; si no forma parte del sistema, no debe ser incorporada a él. La derogación puede ser caracterizada en términos de rechazo más eliminación de las proposiciones rechazadas. Y si bien no tiene sentido derogar las normas inexistentes, tiene perfecto sentido rechazarlas.

El acto de permitir puede ser explicado como rechazo de prohibiciones (existentes o futuras). La caracterización de permisiones en términos de derogación de normas prohibitivas ya ha sido explorada, por ejemplo, por Alf Ross (en Directives and Norms), pero en su teoría sólo es posible permitir actos prohibidos. La distinción entre derogación y rechazo hace posible la permisión de actos que no 
están prohibidos. De esta manera cabe trazar una distinción entre permisos negativos (mera no prohibición) y permisos positivos (rechazo de la prohibición), análoga a la de permisos fuertes y débiles.

En definitiva llegamos a la conclusión de que las dos concepciones usan diferentes lenguajes, con capacidad de expresión similar: las distinciones conceptuales que aparecen en la concepción hilética pueden también ser expresadas en la concepción expresiva (pero esto, como veremos en seguida, no es del todo así).

La concepción expresiva parecía tener considerables ventajas, aunque algunas resultaron a la postre más aparentes que reales. Una ventaja que probablemente sea más aparente que real, pero que nos pareció tal cuando escribimos el artículo, es que permite eludir la principal dificultad de la lógica de normas: como las normas carecen de los valores de verdad (no son ni verdaderas ni falsas), no es claro cómo han de justificarse las relaciones de inferencia o consecuencia lógica entre las normas. En la concepción expresiva es suficiente una lógica de las proposiciones normativas, que tienen valores de verdad. Posteriormente, Alchourrón logró (a mi modo de ver con éxito) superar esta dificultad de fundamentación de una genuina lógica de normas, de modo que esto que nos parecía una importante ventaja perdió su importancia.

Una ventaja auténtica de la concepción expresiva se da en el plano ontológico, pues reduce la necesidad de postular entidades abstractas, como (enunciados con) significados prescriptivos. Pero así como la concepción expresiva tiene ventajas, tiene también sus problemas.

El principal problema consiste en las normas condicionales. Hasta ahora no se ha logrado una representación simbólica satisfactoria de tales normas. No se las puede simbolizar con «p >!q», porque esta expresión está mal formada (ya hemos visto que «!q», no expresa un enunciado y no puede entrar en combinaciones proposicionales con otros enunciados). En un artículo publicado en 1984 en el volumen de homenaje a Ota Weinberger, titulado «Bedingungsnormen - ein Prüfstein für Normenlogik» («Normas condicionales piedra de toque para la lógica de normas») G. H. von Wright trató de defender la simbolización de las normas condicionales mediante $\langle p\rangle$ ?q», pero su intento no resultó del todo satisfactorio, principalmente porque hace imposible el modus ponens: de la norma condicional «Si llueve, Manolo debe cerrar la ventana» y de la proposición de que llueve no se infiere que Manolo debe cerrar la ventana. Este resultado es incompatible con intuiciones nuestras muy firmes.

Tal fue el principal motivo para la vuelta a la concepción hilética. El otro motivo es que si bien esta concepción exige aceptar fuertes 
presupuestos ontológicos, el simbolismo resultante es mucho más simple y más fácil de manejar en la práctica.

6. Uno de los temas de discusión, en la actual Filosofía del Derecho, es el que tiene que ver con el problema de la justificación de decisiones judiciales. En varias ocasiones tú has sostenido que el modelo deductivo de justificación es el único adecuado para reconstruir la forma en que se justifican las sentencias de los jueces. En particular, te muestras totalmente escéptico acerca de la posibilidad de reemplazar ese modelo por uno que se sustente en la denominada teoría de la argumentación. Ello es así, primordialmente, porque entiendes que esta clase de enfoque pretende una sustitución de las reglas de inferencia lógica deductiva por reglas de discurso que habiliten una ampliación de las conclusiones que se pueden obtener a partir de determinadas premisas. Sin embargo, el propósito de una teoría de ese tipo puede ser entendido de otra manera, al menos desde el punto de vista de sus defensores. Hay casos los denominados «casos difíciles») en los que el problema interesante, desde el punto de vista de la justificación de la decisión final, consiste en que el juez tiene que elegir entre premisas alternativas. En este sentido, es posible que las teorías de la argumentación pretendan suministrar criterios para el control racional de la elección de premisas. Como el punto de partida parece ser, precisamente, la ausencia de premisas, la lógica estándar no sería utilizable. ¿Qué opinas sobre esta manera de entender la pretensión de ese enfoque teórico de los problemas de justificación?

En primer lugar, nunca dije que el modelo deductivo de justificación sea el único adecuado para la reconstrucción de las decisiones judiciales. Lo que sostuve y sostengo es que es un modelo adecuado, pero esto no excluye la posibilidad de elaborar otros.

El propósito de buscar criterios para el control racional de la elección de las premisas me parece muy loable. Lamentablemente la teoría de la argumentación no ha logrado hasta ahora suministrar reglas que permitan establecer relaciones jerárquicas entre las premisas $\mathrm{y}$, de esta manera, proporcionar criterios racionales para la elección de las premisas mejores.

Por otra parte, si el punto de partida para la elaboración de tales reglas es la idea de que la lógica estándar no es utilizable debido a la ausencia de premisas, se trata de un error. La lógica es perfectamente utilizable: precisamente una manera (aunque ciertamente no la única) de suministrar pautas racionales para su evaluación y subsiguiente elección consiste en comparar las consecuencias lógicas que se siguen de unas y otras premisas. En otras palabras, un método para 
elegir uno entre varios conjuntos de premisas alternativas consiste en derivar de cada uno de ellos sus consecuencias lógicas para elegir luego aquel conjunto que conduce a consecuencias mejores, más justas o más convenientes. Esta operación requiere, sin duda, el uso de las reglas de inferencia de la lógica deductiva. Creo que los jueces recurren con frecuencia a este método, aun cuando rara vez lo hacen en forma explícita.

Sigo siendo, pues, escéptico respecto de la utilidad de la teoría de argumentación para el problema de la justificación de las sentencias judiciales.

7. Con frecuencia, los teóricos de la argumentación asocian su propuesta con una revisión de las relaciones entre derecho y moral. Tú eres un partidario consecuente de una posición positivista según la cual no tienen por qué existir relaciones necesarias de tipo conceptual entre moral y derecho, lo que acompañas con un declarado escepticismo en materia de ética normativa. En alguna oportunidad has sostenido que existe una relación fuerte de coherencia entre ambas posiciones. Esto parece comprensible si se parte del escepticismo. Pero, ¿por qué pensar que sucede lo mismo en la dirección inversa? ¿Por qué no sería posible sostener que hay diferencias conceptuales entre derecho y moral y, simultáneamente, admitir un cierto grado de objetividad en las discusiones morales de carácter normativo?

Lo que tú llamas mi «positivismo consecuente» tiene dos ingredientes: la tesis de la separación (conceptual) entre el derecho y la moral y el escepticismo en materia de ética normativa. Y es cierto que la primera está basada en el segundo. Este último implica la negación del derecho natural o de una moral objetiva: no creo en la existencia de tales cosas, porque no creo que las normas (inclusive normas morales) puedan ser calificadas como verdaderas u objetivamente válidas. (En contextos de ética normativa el término «validez» es simplemente otra palabra para «verdad», pero tiene el mismo sentido). Mi escepticismo ético tiene, a su vez una base triple.

En primer lugar, la definición de verdad como correspondencia: una expresión (oración, enunciado, proposición) es verdadera si, y sólo si, corresponde al hecho que describe. Esta es la idea básica de la vieja teoría de la verdad como correspondencia de la tradición Aristóteles-Tarski. Creo firmemente en esta teoría; más aún, diría que las otras teorías que se presentan como rivales, como la de coherencia, no son en realidad teorías de la verdad, sino del conocimiento de la verdad. En lugar de suministrar una definición de la verdad, nos proporcionan criterios para afirmar que conocemos la verdad de una proposición. 
En segundo lugar, mi escepticismo ético se basa en una tesis ontológica: creo que no existen hechos normativos (o razones objetivas para actuar, de acuerdo con la terminología hoy día en boga). Ahora bien, si las normas describen algo, tienen que describir hechos normativos o valorativos y si no existen tales hechos, las normas no pueden ser verdaderas, ya que no hay nada que puedan describir.

Esta conclusión es reforzada, en tercer lugar, por una tesis semántica: las normas no son descriptivas, sino prescriptivas. Su relación con la realidad es de tal naturaleza que el problema de la verdad ni siquiera se plantea.

De ahí se sigue que las normas morales no pueden ser calificadas como verdaderas u objetivamente válidas. Su aceptación se basa, en última instancia, en actitudes y preferencias individuales o sociales. Cabe subrayar que mi escepticismo no es meramente cognoscitivo (no se puede conocer verdades morales), sino ontológico (no hay verdades morales). Esto no quiere decir que no haya posibilidad de discrepancias éticas genuinas o que no se pueda aducir argumentos racionales en favor de una posición ética. Pero tales argumentos y discrepancias sólo son posibles dentro del marco común de ciertas normas o valores básicos compartidos.

Ahora bien, si no hay un derecho natural o una moral objetiva, no hay tal cosa como la relación necesaria entre el derecho y la moral. Puede haber muchos sistemas morales y no cabe duda de que de hecho todo orden jurídico positivo está basado en ciertas creencias y/o valoraciones morales, pero no está necesariamente (por razones conceptuales) ligado a algún sistema moral en particular.

Pero tu pregunta apunta en otra dirección: ¿acaso no se puede abandonar el escepticismo ético, pero mantener la tesis de la separación entre derecho y moral? O dicho en otros términos: ¿no se puede creer en la verdad moral y al mismo tiempo sostener que hay diferencias conceptuales entre derecho y moral? Creo que la respuesta depende de lo que ha de entenderse por «diferencias conceptuales». La tesis de la separación (o inexistencia de conexiones necesarias) entre derecho y moral puede formularse de diversos modos, pero la idea central parece ser ésta: una norma jurídica (o un orden jurídico) puede no ser moral e incluso puede ser inmoral, sin dejar de ser una norma jurídica (o un orden jurídico). En consecuencia, una conducta puede ser jurídicamente obligatoria sin ser moralmente obligatoria (para ciertos sistemas morales) e incluso pueden estar moralmente prohibida (en algún sistema moral). Ahora bien, si hay una moral privilegiada, cuyas normas son verdaderas, entonces uno debe hacer lo que esas normas prescriben, y si hay otras normas que prescriben algo incompatible con las normas morales, esto no se debe hacer. 
Para esta posición sería contradictorio afirmar que, de acuerdo al derecho, $\mathrm{p}$ es obligatorio (en el sentido de que uno debe hacer p) y sostener al mismo tiempo que, conforme a la moral, p no es obligatorio o prohibido (uno no debe hacer p). No hay tal cosa como el acto de «hacer $\mathrm{p}$ conforme al derecho» o el acto de «hacer p conforme a la moral»; sólo hay actos de hacer $\mathrm{p}$ o de no hacer (= omitir). Por tanto, o bien uno debe, o bien uno no debe hacer $\mathrm{p}$.

En este sentido, si «admitir cierto grado de objetividad en las discusiones morales de carácter normativo» significa aceptar que hay verdad moral, la distinción conceptual entre derecho y moral se vuelve insostenible. Más aún, la existencia del derecho (entendiendo por tal el derecho positivo) se torna problemática. ¿Para qué dictar normas jurídicas si ya sabemos qué debemos hacer? Como ya decía Kelsen, ¿acaso no es insensato pretender iluminar a la luz solar? Podría pensarse que la relación entre el derecho positivo y la moral sería en tal caso similar a la que se daba, según el califa Omar, entre la biblioteca de Alejandría y el Corán. Pero aun sin ser tan extremistas como Omar, tendríamos que admitir que el derecho positivo se reduce a un papel puramente supletorio; sólo tendría sentido legislar sobre materias moralmente indiferentes, como la dirección del tráfico o el color de la tinta en los escritos judiciales. Incidentalmente, el gran problema de los partidarios de la teoría de las razones para actuar (que es una forma larvada de jusnaturalismo) es la justificación del derecho positivo: véase al respecto el excelente artículo de Juan Carlos Bayón en Doxa 10.

Cabe concluir, pues, que el abandono del escepticismo ético obliga a abandonar la tesis de la separación entre derecho y moral. Y también vale la conversa: la tesis de la separación es incompatible con el objetivismo moral.

Quisiera agregar una advertencia. Mi respuesta a esta pregunta (y a las dos siguientes) adolece de excesiva simplificación; para no alargarla en exceso y por consideración a Doxa y sus lectores, tuve que pasar por alto algunos matices relevantes. Pero con esta reserva refleja mis puntos de vista sobre esta materia tan controvertida.

8. Una de tus propuestas es la distinción de varios sentidos en los que puede decirse que «existe» una norma. Uno de ellos se refiere a la "existencia fáctica», con respecto al cual admites la idea de Hart acerca del punto de vista interno como una característica definitoria. Los que adoptan ese punto de vista -en especial, los juecescreen que las normas que aceptan son «obligatorias», esto es, normas que deben ser cumplidas. Como este «deber» no puede ser jurídico, un número importante de teóricos actuales concluyen que hay que admitir una asociación conceptual del derecho con la moral, al 
menos, con las creencias morales de los jueces. En varias oportunidades has negado que se tenga que obtener esa conclusión. ¿De qué otra manera habría que entender, entonces, la «obligatoriedad» en la que creen los que asumen el punto de vista interno?

En primer lugar, no hay que confundir la moral con las creencias morales de los jueces. Los jueces, como todos los demás mortales, pueden ( $\mathrm{y}$ a menudo suelen) tener creencias morales de diversa índole, muchas de ellas, equivocadas. En segundo lugar, esta tesis es peligrosamente ambigua: si por «moral» entendemos «alguna moral», la tesis es totalmente trivial e inocua. Sólo significa que para la existencia fáctica de un orden jurídico tiene que haber un cierto grado de coincidencia entre sus normas y las creencias morales de los jueces (y otros órganos). Pero si por «moral» entendemos el sistema de moral ideal (cuyas normas son verdaderas), la tesis es seguramente falsa por dos razones: primero, porque (en mi opinión) no existe tal sistema moral privilegiado; y segundo, porque para la existencia fáctica del derecho basta que éste coincida con las creencias morales que de hecho mantienen los jueces y otros órganos, aun cuando tales creencias no coincidan con la moral.

9. En numerosos trabajos admites que la justicia es un criterio sustantivo para evaluar sistemas normativos, en especial, sistemas jurídicos, a la par de los criterios puramente formales como lo son la consistencia y la completitud. Sin embargo, es notoria tu creencia acerca de la imposibilidad de determinar el contenido de ese criterio. En el ámbito de la filosofía analitica, a partir de "A Theory of Justice», de J. Rawls (1971), se sostiene que a partir de ciertos presupuestos -como en cualquier otra discusión teóricaes posible obtener de manera racional ciertas conclusiones acerca de criterios de justicia. Sería interesante que nos expongas tu opinión sobre esta manera de abordar un problema básico de ética normativa. En especial, ¿cuál sería el inconveniente -si es que lo hay-para la utilización de los resultados de discusiones como la de Rawls como criterios para evaluar los sistemas jurídicos desde el punto de vista de su justicia o injusticia?

Lo que dije respecto de las normas morales vale también para los principios de justicia. No hay principios de justicia verdaderos y, en consecuencia, no se puede determinar racionalmente cuáles son esos principios. Esto no hace imposible -como creen algunos- toda discusión racional sobre cuestiones de justicia; pero tal discusión sólo es posible dentro del marco de ciertos principios o varios «sistemas» de justicia y si bien no es posible decidir en forma racional cuál de 
ellos es el «verdadero», es perfectamente posible determinar racionalmente qué consecuencias se siguen de adoptar tales o cuales principios básicos.

Desde este punto de vista el libro de Rawls y otros que siguen su línea son sumamente interesantes y valiosos. Rawls en particular ha explorado muy bien una cierta concepción de justicia (la concepción que se podría caracterizar como democrática y liberal) y ha mostrado sus implicaciones. (Con todo, creo que Rawls es excesivamente optimista. Cree, por ejemplo, que es posible derivar mediante «riguroso razonamiento deductivo» qué cursos de acción elegirían las personas en la posición originaria. Esta afirmación revela cierto grado de ingenuidad y la prueba es que en ningún lugar del libro de Rawls se encuentran deducciones formales, ya que sólo es posible hacer deducciones rigurosas en un lenguaje formalizado). Si, en cambio, el libro de Rawls es presentado como el desarrollo de la justicia, no puedo reprimir una leve sonrisa escéptica.

Se sigue de lo dicho que no hay ningún inconveniente en utilizar los resultados de discusiones como la de Rawls para evaluar los sistemas jurídicos desde el punto de vista de su justicia, siempre que uno esté consciente de sus límites. La concepción de la justicia de Rawls no es ciertamente la única posible y tampoco puede aspirar a revelarnos la verdadera justicia, porque no hay tal cosa. Pero para los que comparten ciertos valores básicos, la discusión de Rawls es muy fructífera y útil.

Por eso discrepo con tu formulación: los presupuestos de Rawls no son del mismo tipo que en «cualquier discusión teórica». El análisis de Rawls presupone la adopción de ciertos valores morales fundamentales, que no es necesario aceptar en una discusión científica. 
DOXA-14 (1993)

$\triangle$ 